\title{
Single-course antenatal corticosteroids is related to faster growth in very-low-birth- weight infant
}

Jiajia Jing ${ }^{1 \dagger}$, Yiheng Dai ${ }^{2 \dagger}$, Yanqi $\mathrm{Li}^{3 \dagger}$, Ping Zhou ${ }^{4}$, Xiaodong $\mathrm{Li}^{5}$, Jiaping Mei ${ }^{6}$, Chunyi Zhang ${ }^{7}$, Per Trop Sangild ${ }^{3,8}$, Zhaoxie Tang ${ }^{1}$, Suhua $\mathrm{Xu}^{1}$, Yanbin $\mathrm{Su}^{1}$, Xiaoying $\mathrm{He}^{1}$ and Yanna Zhu ${ }^{1 *}$ (i)

\begin{abstract}
Background: Antenatal corticosteroids (ACS) treatment is critical to support survival and lung maturation in preterm infants, however, its effect on feeding and growth is unclear. Prior preterm delivery, it remains uncertain whether ACS treatment should be continued if possible (repeated course ACS), until a certain gestational age is reached. We hypothesized that the association of single-course ACS with feeding competence and postnatal growth outcomes might be different from that of repeated course ACS in very-low-birth-weight preterm infants.

Methods: A multicenter retrospective cohort study was conducted in very-low-birth-weight preterm infants born at 23-37 weeks' gestation in South China from 2011 to 2014. Data on growth, nutritional and clinical outcomes were collected. Repeated course ACS was defined in this study as two or more courses ACS (more than single-course). Infants were stratified by gestational age (GA), including GA $<28$ weeks, 28 weeks $\leq \mathrm{GA}<32$ weeks and 32 weeks $\leq$ $\mathrm{GA}<37$ weeks. Multiple linear regression and multilevel model were applied to analyze the association of ACS with feeding and growth outcomes.

Results: A total of 841 infants were recruited. The results, just in very-low-birth-weight preterm infants born at 2832 weeks' gestation, showed both single and repeated course of ACS regimens had shorter intubated ventilation time compared to non-ACS regimen. Single-course ACS promoted the earlier application of amino acid and enteral nutrition, and higher rate of weight increase $(15.71 ; 95 \% \mathrm{Cl}$ 5.54-25.88) than non-ACS after adjusting for potential confounding factors. No associations of repeated course ACS with feeding, mean weight and weight increase rate were observed.

Conclusions: Single-course ACS was positively related to feeding and growth outcomes in very-low-birth-weight preterm infants born at 28-32 weeks' gestation. However, the similar phenomenon was not observed in the repeated course of ACS regimen.
\end{abstract}

Keywords: Antenatal corticosteroids, Growth, Nutrition, Very low birth weight

\footnotetext{
* Correspondence: zhuyn3@mail.sysu.edu.cn

†Jiajia Jing, Yiheng Dai and Yanqi Li are contributed equally and should be considered shared first authors.

'Department of Maternal and Child Health, School of Public Health, Sun Yat-sen University, No. 74 Zhongshang 2nd Road, Guangzhou 510080, China Full list of author information is available at the end of the article
}

(c) The Author(s). 2021 Open Access This article is licensed under a Creative Commons Attribution 4.0 International License, which permits use, sharing, adaptation, distribution and reproduction in any medium or format, as long as you give appropriate credit to the original author(s) and the source, provide a link to the Creative Commons licence, and indicate if changes were made. The images or other third party material in this article are included in the article's Creative Commons licence, unless indicated otherwise in a credit line to the material. If material is not included in the article's Creative Commons licence and your intended use is not permitted by statutory regulation or exceeds the permitted use, you will need to obtain permission directly from the copyright holder. To view a copy of this licence, visit http://creativecommons.org/licenses/by/4.0/. The Creative Commons Public Domain Dedication waiver (http://creativecommons.org/publicdomain/zero/1.0/) applies to the data made available in this article, unless otherwise stated in a credit line to the data. 


\section{Background}

Antenatal corticosteroids (ACS) treatment is commonly used worldwide as the standard treatment for pregnant women at risk of preterm labor [1]. European consensus guidelines for the management of neonate respiratory distress syndrome (RDS) in preterm infants recommended that single-course ACS should be used at least $24 \mathrm{~h}$ before delivery $<34$ gestational age (GA). Repeated course ACS may be used if preterm labor is estimated to be $<32$ GA and the first course was given more than 12 weeks earlier [2]. Different ACS regimens were critical to support survival [3] and lung maturation [4, 5], whereas, had unclear effects on feeding and growth in very-low-birth-weight (VLBW) preterm infants. Moreover, the risk-to-benefit ratio for repeated course ACS application was still ambiguous $[1,6,7]$.

The effects of ACS were different between single and repeated course treatments. Meta-analyses $[8,9]$ showed that single-course ACS can effectively reduce the risk of RDS, necrotizing enterocolitis (NEC), and infection. Repeated course ACS can also decrease the risk of RDS, but accompanied some side effects. For instance, several studies reported that repeated course ACS seemed to be negatively correlated with weight growth in the uterus [10] or not $[11,12]$. Whereas, the similar reduction trend of weight was not observed when at discharge [13] or in 2-3 years later [14-17]. We should notify that those results adjusted for the maternal factors but ignored postnatal factors, such as nutritional factors. Many studies have demonstrated that ACS improved intestinal maturation in a manner similar to lungs [18-20]. However, there was a lack of evidence on the relationship between ACS and nutritional outcomes. This has prompted us to conduct further studies on the association of ACS with postnatal growth and feeding outcomes.

In summary, we aimed to explored whether ACS, with single-course or repeated course were associated with growth, nutritional outcomes (e.g. time to initiate parenteral and enteral feeding, time to reach full enteral feeding) and clinical outcomes (e.g. days on mechanical ventilation, NEC incidence, mortality) in VLBW infants based on a retrospective cohort.

\section{Materials and methods}

\section{Study design and subjects}

The retrospective cohort study was a part of the NEOMUNE study [21], which was performed in five neonatal intensive care units (NICUs) from 2011 to 2014 in Guangdong province, China. Inclusion criteria were infants inborn or transferred to the NICU within $24 \mathrm{~h}$ after birth, < 37 weeks' gestation and < $1500 \mathrm{~g}$ at birth, survived for at least $24 \mathrm{~h}$. Exclusion criteria included major congenital abnormalities or congenital metabolic diseases.

\section{Exposure and outcomes}

The VLBW preterm infants were classified as non- ACS group, single-course ACS group and repeated course ACS group. Since a systematic review reported that the scope of GA for which the ACS provides benefits has been controversial [14]. In the present study, the participants were stratified by gestational age as three groups-GA $<28$ weeks, 28 weeks $\leq$ $\mathrm{GA}<32$ weeks and 32 weeks $\leq \mathrm{GA}<37$ weeks. Single-course ACS in the study meant that $24 \mathrm{mg}$ of dexamethasone intramuscularly in $6 \mathrm{mg}$ per dose every $12 \mathrm{~h}$ for a total of four doses. Repeated course ACS was defined in this study as two or more courses ACS (more than single-course). The pregnant women exposed to fewer than 4 doses were assigned to the single-course ACS group. Information including maternal and neonatal demographics (maternal age, delivery mode, GA, biological sex, APGAR score at $5 \mathrm{~min}$ and anthropometrics at birth), ACS use, type of enteral nutrition (complete breastfeeding, mix feeding, 100\% preterm formula milk), nutritional and clinical data (initiation day of parenteral and enteral feeding, time to reach full enteral feeding, days on intubated ventilatory and non-invasive ventilator, NEC, intrauterine growth retardation [IUGR] and so on) were collected. In the present study, complete breastfeeding meant $100 \%$ own mother's milk. Postnatal weight data were meticulously measured weekly during hospitalization. Time to reach full enteral feeding was defined as time to achieving enteral feeding volumes of $150 \mathrm{~mL} \cdot \mathrm{kg}^{-1} \cdot \mathrm{d}^{-1}$ [22]. IUGR was defined as retardation of fetal development resulting in small size in relation to gestational age, using less than the tenth percentile as a cutoff growth criterion [23]. The recommended formula for growth velocity was the exponential method published by Patel et al. [24]. Growth velocity $\left(\mathrm{g} \cdot \mathrm{kg}^{-1} \cdot \mathrm{d}{ }^{-1}\right)=[1000 \times \ln$ (Weight Day ${ }_{n} /$ Weight Day ${ }_{1}$ )] / (Day ${ }_{n}-$ Day $_{1}$ ). All data were collected until 37 postmenstrual age or at discharge (including discharge upon parental request), or death.

\section{Statistical analyze}

All statistical analyses were performed using the software SPSS 25.0 (SPSS Inc. Chicago, IL). Cases with lost (or missed) ACS information were eliminated. Data were summarized using means and SDs, medians and interquartile ranges (IQRs), numbers and percentages, as appropriate. Kruskal-Wallis $H$ test and $X^{2}$ test were used to compare the nutritional and clinical outcomes among ACS groups. Mann-Whitney test was used for post hoc analysis. Multiple linear regression was used to analyze the association of ACS with nutritional and clinical outcomes. Multilevel model was used to analyze the association between ACS and early weight growth trajectories. In multilevel model, the coefficients for ACS were related to differences in mean weight, for interactions between the ACS and time could be interpreted to indicate 
differences in mean weight varied over time (weight increase rate).

\section{Missing data}

Data in this study were collected from routine records of clinical systems, for this reason, the proportions of missing data in each variable were small, including $0.95 \%$ for maternal age, $0.59 \%$ for multiple births, $0.23 \%$ for cesarean section, $3.68 \%$ for birth length, $0.95 \%$ for APGAR score, $0.83 \%$ for intubation ventilation, $1.55 \%$ for non-invasive ventilation, $2.85 \%$ for extra oxygen supply, $3.92 \%$ for regain birthweight, $0.24 \%$ for inpatient time, and $0.59 \%$ for amino acid introduction and duration. Multiple imputation was not performed.

\section{Sensitivity analyses}

We used stratified analysis to address confounding factor GA, double entry to reduce information bias and missing data bias. Additionally, the inclusion and exclusion criteria were strictly followed to avoid selection bias. The intrauterine status of some unmeasured confounding may have an impact on nutrition and growth outcomes. In order to ascertain the sensitivity of our results to different health status in utero, analyses were performed to evaluate the association of ACS regimens with nutritional outcomes and postnatal growth in IUGR or non-IUGR VLBW preterm infants in supplementary material.

\section{Results}

A total of 1178 VLBW preterm infants were identified. Two hundred forty-six cases were excluded for major congenital abnormalities, metabolic diseases or transfer to another hospital within $24 \mathrm{~h}$ of birth. Ninety-one cases without ACS information were eliminated. As a result, 841 VLBW preterm infants were recruited in the study, including 456 (54.2\%) in non-ACS group, 162 (19.3\%) in single-course group and 223 (26.5\%) in repeated course group. Average follow-up time was 39 days. The median GA and birthweight were 30.1 (28.931.6) weeks and 1300 (1150-1400) g, respectively.

\section{Association of ACS application with clinical and nutritional outcomes}

In terms of nutrition outcomes, compared with nonACS group, single-course ACS group had higher proportion of complete breastfeeding in feeding pattern in $\mathrm{GA}<28$ weeks, and had significant earlier application of amino acid and enteral nutrition in 28 weeks $\leq \mathrm{GA}<32$ weeks. We also found repeated course ACS group had larger proportion of mixed feeding, and less 100\% preterm formula milk in feeding pattern in 28 weeks $\leq \mathrm{GA}<$ 32 weeks (Table 1). After adjustment for potential confounding factors of birth demographics and respiratory- related indicators, single-course ACS showed positive relationship to the introduction of amino acid and enteral nutrition in 28 weeks $\leq \mathrm{GA}<32$ weeks, however, repeated course ACS showed no significant correlation with nutritional outcomes (Table 2).

Pertaining to clinical outcomes, both single-course ACS group and repeated course ACS group had shorter time on intubation ventilation support compared with non-ACS group. Repeated course group had the highest rate of cesarean section among the three groups only in 28 weeks $\leq \mathrm{GA}<32$ weeks. No differences in clinical outcomes were found between single-course ACS group and repeated course ACS group (Table 1).

\section{Association of ACS application with postnatal weight growth}

The weight growth trajectories of VLBW preterm infants were shown in Fig. 1. The trajectories of mean weight (shown in Fig. 1. B) and weight growth velocity (shown in Fig. 1. D) were also examined separately by different birth GA. Differences in the weight-growth curve trajectories were assessed in Table 3.

In unadjusted model, single-course ACS group had a greater average weight over time compared with the repeated course ACS group. Also, single-course ACS and repeated course ACS groups demonstrated higher weight increase rate over time compared with the nonACS group. After adjusting for confounding factors of birth demographics, mode of delivery, nutritional and respiratory-related indicators, single-course ACS group had higher weight increase rate compared with nonACS group, however, there were no differences in mean weight among groups. Finally, identical growth advantage for single-course ACS were observed in VLBW preterm infants born at 28-32 weeks' gestation. No differences in mean weight and weight growth rate among non-ACS, single-course and repeated course ACS treatments were found in other GA group in multivariable analysis.

\section{Discussion}

Previous studies showed unclear effects of ACS on postnatal growth and feeding in VLBW preterm infants. The present study showed a close relationship between singlecourse ACS application and the remarkable improvement in terms of amino acid introduction, enteral nutrition introduction, and weight increase rate in VLBW infants born at 28-32 GA. Additionally, both single and repeated course of ACS regimens had shorter intubated ventilation time compared to non-ACS regimen.

Single-course ACS positively correlated with earlier application of amino acid and enteral nutrition with VLBW preterm infants with 28-32 GA. On the contrary, repeated course ACS did not show any association in all 


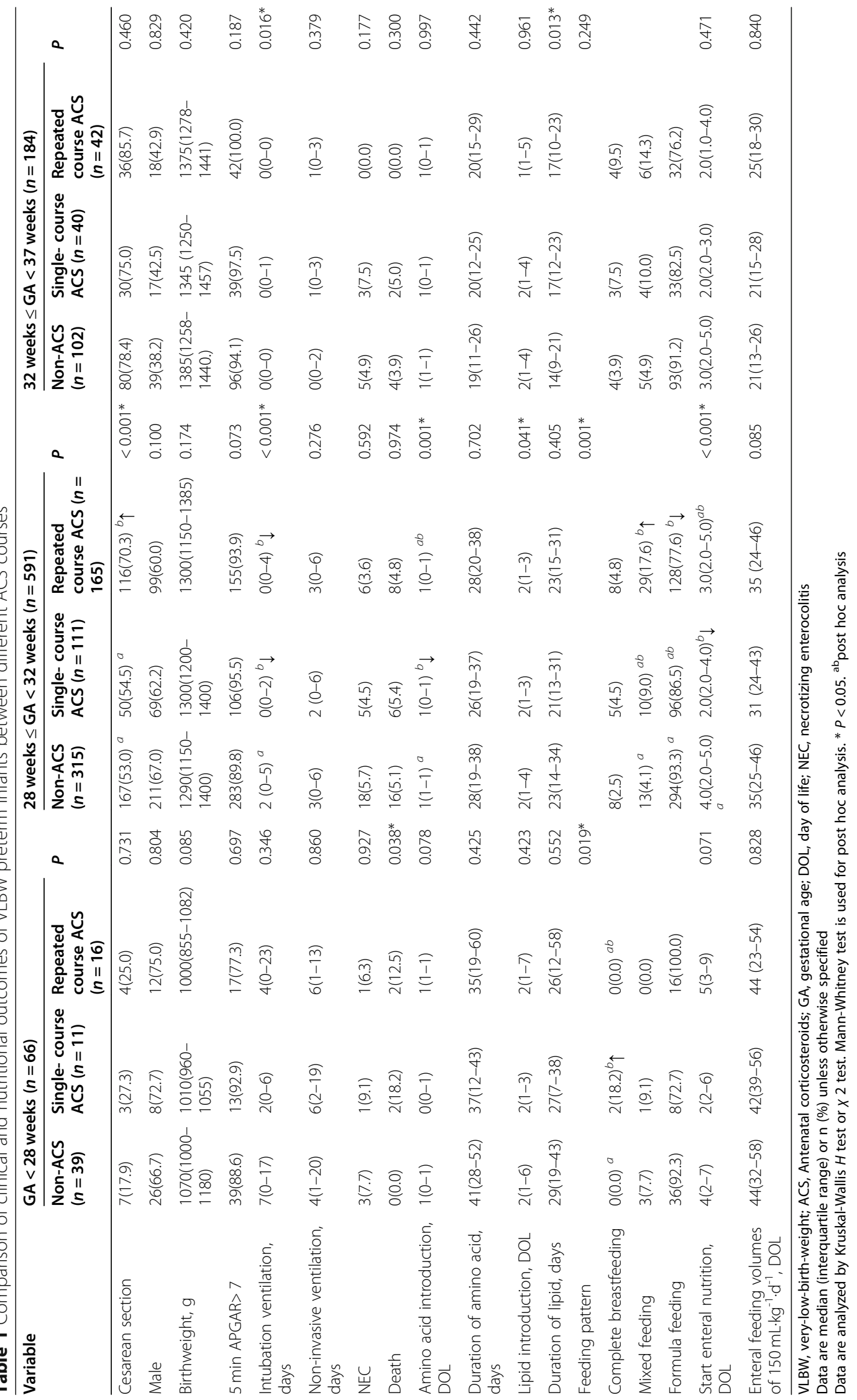


Table 2 Multivariate analysis of ACS courses association with nutritional outcomes in VLBW infants stratified by GA

\begin{tabular}{|c|c|c|c|c|}
\hline \multirow[t]{2}{*}{ Variable } & \multicolumn{2}{|l|}{ Total } & \multicolumn{2}{|c|}{28 weeks $\leq \mathrm{GA}<32$ weeks } \\
\hline & Single-course ACS & Repeated course ACS & Single-course ACS & Repeated course ACS \\
\hline Amino acid introduction $^{a}$ & $-0.11(-0.70,-0.15)^{*}$ & $-0.05(-0.44,0.04)$ & $-0.09(-0.71,-0.04)^{*}$ & $-0.04(-0.44,0.14)$ \\
\hline Lipid introduction ${ }^{b}$ & $-0.04(1.42,0.38)$ & $-0.05(-1.35,0.23)$ & $-0.02(-1.46,0.76)$ & $-0.05(-1.57,0.34)$ \\
\hline Enteral nutrition introduction ${ }^{c}$ & $-0.08(-1.35,-0.11) *$ & $-0.04(-0.87,0.22)$ & $-0.09(-1.52,-0.01) *$ & $-0.05(-1.08,0.22)$ \\
\hline Enteral feeding volumes of $150 \mathrm{~mL} \cdot \mathrm{kg}^{-1} \cdot \mathrm{d}^{-1 \mathrm{~d}}$ & $-0.03(-3.70,0.94)$ & $0.006(-1.89,2.30)$ & $-0.03(-4.22,1.50)$ & $0.009(-2.24,2.84)$ \\
\hline
\end{tabular}

Data are adjusted linear regression coefficient $(95 \% \mathrm{Cl})$, refer to non-ACS

$V L B W$ very-low-birth-weight, $A C S$ Antenatal corticosteroids, GA gestational age

*multiple linear regression shows significant outcomes. No significant outcomes were found in $G A<28$ weeks or 32 weeks $\leq \mathrm{GA}<37$ weeks group

a adjusted for GA, 5 min APGAR score

b adjusted for GA, 5 min APGAR score and amino acid introduction

c adjusted for GA, birth weight, cesarean section, lipid introduction and amino acid introduction

d adjusted for GA, birth weight, cesarean section, lipid introduction, amino acid introduction and feeding pattern

GA groups. Previous studies showed that ACS improved the bowel maturation in a manner similar to the lung, that is due to its gastrointestinal tract maturation enhancement effect and anti-inflammatory properties [25, 26]. Animal researches [18, 19] and human studies [20] suggested that ACS could promote the secretion of gut hormones and the growth of the gastrointestinal tract. Enteral nutrition could be introduced when there was bowel motility. The bowel motility patterns were abnormal and incompletely developed before 28 GA [27]. This may be the reason why we did not observe the difference between groups before $28 \mathrm{GA}$. Motilin receptors and cyclic motilin release are present after 32 GA [27]. Therefore, we speculated that the effect of ACS exposure on the time to start enteral feeding became insignificant after 32 GA. A study [28] published in a Chinese journal has the similar view. The IUGR rate in repeated course ACS was higher compared with single-course ACS. When stratified according to IUGR or non-IUGR, the above conclusions were consistent in the non-IUGR group (supplementary material).

The results from the present study showed that although there was no difference in birthweight among non-ACS, single-course ACS and repeated course ACS

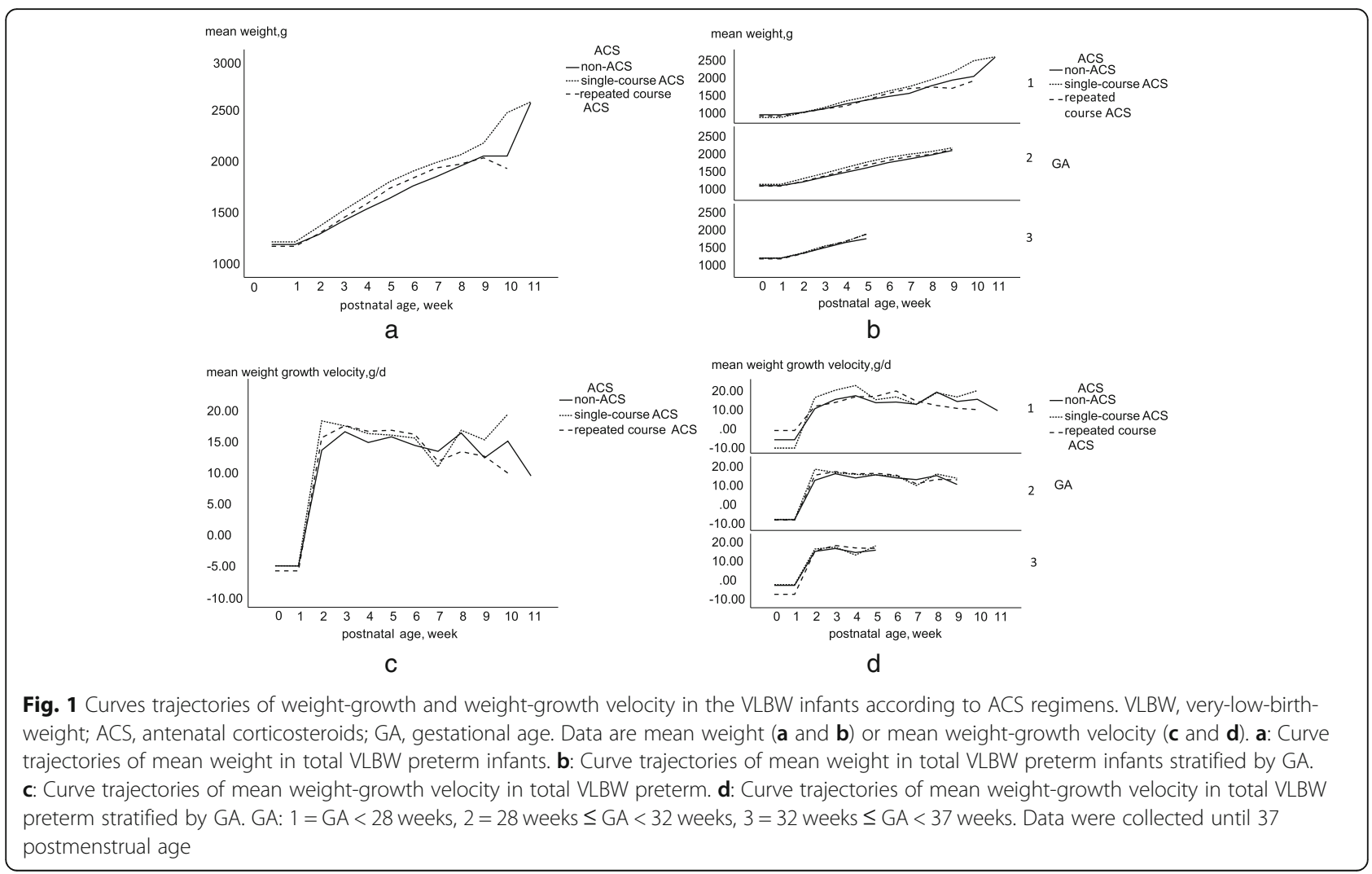


Table 3 Relationship between ACS with weight changes during hospitalization in VLBW preterm infants

\begin{tabular}{|c|c|c|}
\hline Variable & Unadjusted coefficient & Adjusted coefficient $^{a}$ \\
\hline \multicolumn{3}{|l|}{ Total } \\
\hline Postnatal age, week & $45.52(40.91,50.12) *$ & $74.23(56.03,92.42) *$ \\
\hline Non-ACS & 0.00 (Reference) & 0.00(Reference) \\
\hline Single-course & 23.54(-9.32,56.39) & $1.54(-29.76,32.84)$ \\
\hline Repeated course & $-19.29(-48.41,9.82)$ & $-12.61(-40.30,15.06)$ \\
\hline Time* single-course & $18.24(10.07,26.42) *$ & $14.75(6.02,23.49) *$ \\
\hline Time* repeated course & $10.12(2.94,17.31) *$ & $5.48(-2.24,13.21)$ \\
\hline Repeated course & 0.00(Reference) & 0.00(Reference) \\
\hline Single-course & $42.83(5.94,79.71) *$ & $14.15(-20.38,48.70)$ \\
\hline Time $^{*}$ single-course & $8.12(-1.02,17.26)$ & $9.27(-0.41,18.96)$ \\
\hline \multicolumn{3}{|l|}{$G A<28$ weeks } \\
\hline Postnatal age, week & $34.10(19.85,48.35) *$ & $53.59(-21.00,128.20)$ \\
\hline Non-ACS & 0.00(Reference) & 0.00(Reference) \\
\hline Single-course & $-81.72(-201.53,38.09)$ & $-83.94(-211.27,43.38)$ \\
\hline Repeated course & $-38.34(-138.91,62.23)$ & $3.73(-98.58,106.05)$ \\
\hline Time $^{*}$ single-course & $22.00(-6.99,50.98)$ & $20.31(-13.07,53.70)$ \\
\hline Time* repeated course & $4.21(-19.85,28.27)$ & $4.68(-21.17,30.54)$ \\
\hline Repeated course & 0.00(Reference) & 0.00(Reference) \\
\hline Single-course & $-43.38(-179.30,92.55)$ & $-87.68(-232.75,57.38)$ \\
\hline Time $^{*}$ single-course & $17.79(-15.27,50.85)$ & $15.63(-21.84,53.10)$ \\
\hline \multicolumn{3}{|l|}{28 weeks $\leq \mathrm{GA}<32$ weeks } \\
\hline Postnatal age, week & $43.27(37.93,48.61) *$ & $73.43(51.71,95.15)$ * \\
\hline Non-ACS & 0.00(Reference) & 0.00 (Reference) \\
\hline Single-course & $31.99(-4.93,68.90)$ & $10.90(-25.09,46.90)$ \\
\hline Repeated course & $-14.48(-46.59,17.63)$ & $-14.67(-46.41,17.06)$ \\
\hline Time $^{*}$ single-course & $19.99(10.51,29.46) *$ & $15.71(5.54,25.88) *$ \\
\hline Time* repeated course & $10.55(2.36,18.73) *$ & $5.26(-3.66,14.20)$ \\
\hline Repeated course & 0.00(Reference) & 0.00(Reference) \\
\hline Single-course & $46.47(5.51,87.42) *$ & $25.57(-14.02,65.17)$ \\
\hline Time* single-course $^{*}$ & $9.43(-1.05,19.92)$ & $10.44(-0.81,21.69)$ \\
\hline 32 weeks $\leq \mathrm{GA}<37$ weeks $^{\mathrm{b}}$ & & \\
\hline
\end{tabular}

Point estimates and $95 \% \mathrm{Cl}$ of differences in mean weight or weight growth rate are shown

$V L B W$ very-low-birth-weight, ACS Antenatal corticosteroids, GA gestational age

* Significantly different from reference group

${ }^{a}$ Adjusted for sex, feeding pattern, cesarean section rate, time to start enteral nutrition, 5 min APGAR score, GA, multiple birth, amino acid and lipid introduction,

duration of amino acid and lipid

${ }^{b}$ Iteration is terminated but convergence has not been achieved. Validity of the model fit is uncertain

All data were collected until 37 postconceptional age or at discharge

groups, postnatal growth rate was found to be different. Single-course ACS group had higher weight increase rate in infants born at $28-32 \mathrm{GA}$, however, repeated course ACS did not improve the average weight and weight increase rate during hospitalization after adjusting for sex, cesarean section rate, 5 min APGAR score, GA, multiple birth and nutritional factors. Prior animal and human studies have suggested that multiple repeated ACS may impair fetal growth $[29,30]$ or have no effects $[11,12,14]$, Some studies found no association between multiple repeated ACS with adverse effects on growth at discharge [13], in 2-3 years of age or in adolescence [14-17]. These studies measured weight at birth or at single point time after a period of time, while we managed to collect the longitudinal postnatal measurement. A retrospective study reported that ACS did not affect mean weight in the nursery [31], which was largely consistent with our research. Another study [32] 
focused on both mean weight gain and weight growth rate. The researchers measured weight at birth and weekly for 4 weeks or until discharge, and they found infants before 32 GA exposed to repeated course ACS demonstrated postnatal growth acceleration (singlecourse ACS was not concluded in their study), which was consistent with our results before adjusting for postnatal clinical and nutritional status. Considering the above factors, we only found that single-course ACS had higher weight growth rate related to non-ACS.

VLBW preterm infants could experience 'catch-up' growth after birth over the weeks and months [33]. Interestingly, the negative effects of ACS on birthweight [29] may not be observed after birth in a period of time [14]. We observed a more rapidly increase in weight growth rate in the group exposed to single-course ACS at 28-32 GA. This meant that the VLBW preterm infants may recovery from the potential growth inhibitory effects of ACS shortly after birth [32]. The recovery was presumably related to the physiology and nutrition around the time of birth, especially in the repeated course ACS group. The "GA window" (28-32 GA) further illustrated that this recovery may be due to the effects of ACS on the gastrointestinal tract. Of note, fast growth catchup does not necessarily imply a better longterm outcome [34, 35]. The mechanism of influences of different courses ACS on the gastrointestinal tract is still unclear. Therefore, we expect more studies providing evidence for it, as well as the impact on catching growth.

Both single-course and repeated course ACS were associated with shorter time of intubation ventilation in infants born at 28-32 GA, which was consistent with previous researches [14, 16, 36-38]. Moreover, the effects of ACS on clinical outcomes in preterm infants predominately depended on GA, that is mainly because of different stages of fetal organ development seen in various GA stages $[39,40]$. In this study, the duration of intubation ventilation was not different among nonACS, single-course ACS and multi-course ACS groups in infants $<28 \mathrm{GA}$. Observational studies have shown inconsistent findings in infants at the lowest gestations. A multicenter study [41] of infants < 29 weeks' gestation found a higher incidence of respiratory complications in infants exposed to ACS than in those not exposed. However, another large multicenter observational study [42] did not find a difference in the incidence of respiratory complications between the exposed and unexposed ACS groups. The Cochrane review [14, 43] subgroup analysis (4 randomized controlled trials, 102 infants) of those infants $<28 \mathrm{GA}$ also found that the incidence of RDS exposed to ACS did not differ compared to infants who were not exposed. Randomized controlled trials with adequate sample sizes are needed to explain the role of ACS in extremely preterm infants.
A major strength of this study was that we continuously measured the weight gain of VLBW preterm infants during hospitalization, compared with previous studies focusing on separate time points. Our study focused on nutrition-related outcomes during hospitalization, while it was less frequently discussed in previous studies. We found that single-course ACS treatment had the greatest benefit for VLBW infants born at 28-32 weeks, suggesting that more cautions are needed when expanding the use of ACS in clinical practice.

Limitations in the study included that it was a retrospective study in design, with some potentially confounders unmeasured or uncollected, such as specific data of ACS use, maternal history and sociodemographic characteristics. Furthermore, some parents required an early discharge of their infants subsequently some related clinical outcomes were unclear. We did not make a detailed distinction between one repeat course or multiple weekly repeat course in this study, since the questionnaire was designed and the data were collected during 2011-2014, when there were no guideline recommendations for the use of repeated course ACS. The ACS used in these hospitals was dexamethasone, therefore the final conclusions could not represent other medicine treatment regimen.

\section{Conclusions}

In summary, single-course ACS treatment was positively related to parenteral and enteral feeding, as well as weight growth in VLBW preterm infants born at 28-32 weeks' gestation. However, no associations of repeated course ACS with feeding and growth were observed, which indicates that more attention are needed to pay when expanding the use of ACS in clinical practice.

\section{Supplementary Information}

The online version contains supplementary material available at https://doi. org/10.1186/s12884-020-03510-w.

\section{Additional file 1.}

\section{Abbreviations}

ACS: Antenatal corticosteroids; RDS: Respiratory distress syndrome; GA: Gestational age; VLBW: Very-low-birthweight; NEC: Necrotizing enterocolitis; NICU: Neonatal intensive care units; IUGR: Intrauterine growth retardation

\section{Acknowledgements}

We thank the participants, as well as the doctors and nurses involved in this study.

\section{Authors' contributions}

Jj J: Investigation, Formal analysis, Writing - Original Draft Yh D: Investigation, Resources P Z: Investigation, Resources Xd L: Investigation, Resources Jp M: Investigation, Resources Cy Z: Investigation, Resources Yq L: Validation, Writing - Review \& Editing P S: Methodology, Writing - Review \& Editing Zx T: Investigation, Writing - Review \& Editing Sh X: Investigation, Writing Review \& Editing Yb S: Investigation, Writing - Review \& Editing Xy H: 
Investigation, Resources Yn Z: Conceptualization Data Curation, Writing Review \& Editing, Supervision, Project administration. All authors read and approved the final manuscript.

\section{Funding}

This work was supported by Guangdong Provincial Natural Science Foundation (Grant No.2017A030313844); Sanming Project of Medicine in Shenzhen (Grant No. SZSM201803061); the Fundamental Research Funds for the Central Universities in SYSU (Grant No.15ykpy09); An international project "Early Milk and Microbiota to Improve Later Immunity (NEOMUNE)" (Grant No.51000-71030047). The funders had no role in the design, preparation of data, analysis or writing of this article.

\section{Availability of data and materials}

The datasets generated during the current study are not publicly available due to this study was a multicenter study, the agencies were keeping the data confidential but are available from the corresponding author on reasonable request.

\section{Ethics approval and consent to participate}

This study was approved by the ethical committee of Sun Yat-sen University. This study used retrospective methods to collect cohort data information and data were anonymous and were routinely collected as part of clinical care, therefore did not apply for written informed consent form for parents. A contract research organization was responsible for regulatory and safety aspects of the database (Academic Medical Center, Amsterdam, the Netherlands).

\section{Consent for publication}

Not applicable.

\section{Competing interests}

The authors declare that they have no competing interests.

\section{Author details}

'Department of Maternal and Child Health, School of Public Health, Sun Yat-sen University, No. 74 Zhongshang 2nd Road, Guangzhou 510080, China. ${ }^{2}$ Department of Neonatology, Foshan Woman and Children's Hospital, Foshan, China. ${ }^{3}$ Comparative Pediatrics and Nutrition, University of Copenhagen, Copenhagen, Denmark. ${ }^{4}$ Department of Neonatology, Shenzhen Bao'an Maternal and Child Health Hospital, Shenzhen, China. ${ }^{5}$ Department of Neonatology, Shenzhen Nanshan People's Hospital, Shenzhen, China. ${ }^{6}$ Department of Neonatology, Shenzhen Maternity \& Child Health Care Hospital, Shenzhen, China. 'Department of Neonatology, Guangdong Women and Children Hospital, Guangzhou, China. ${ }^{8}$ Department of Pediatrics and Adolescent Medicine, Rigshospitalet, Copenhagen, Denmark.

Received: 22 July 2020 Accepted: 21 December 2020

Published online: 12 January 2021

\section{References}

1. Kemp MW, Schmidt AF, Jobe AH. Optimizing antenatal corticosteroid therapy. Semin Fetal Neonatal Med. 2019;24(3):176-81.

2. Sweet DG, Carnielli V, Greisen G, Hallman M, Ozek E, Te Pas A, et al. European consensus guidelines on the Management of Respiratory Distress Syndrome - 2019 update. Neonatology. 2019;115(4):432-50.

3. G. C. Liggins M, FRCOG, R. N. Howie, MB, MRACP. A Controlled Trial of Antepartum Glucocorticoid Treatment for Prevention of the Respiratory Distress Syndrome in Premature Infants. Pediatrics. 1972;50:515-525.

4. GC L. Premature delivery of foetal lambs infused with glucocorticoids. J Endocrinol 1969:45:515-523.

5. Vermillion ST, Bland ML, Soper DE. Effectiveness of a rescue dose of antenatal betamethasone after an initial single course. Am J Obstet Gynecol. 2001;185(5):1086-9.

6. ACOG. American College of Obstetricians and Gynecologists. ACOG committee opinion No. 713: antenatal corticosteroid therapy for fetal maturation. Obstet Gynecol. 2017;130(2):e102-9.

7. Groom KM. Antenatal corticosteroids after 34 weeks' gestation: do we have the evidence? Semin Fetal Neonatal Med. 2019;24(3):189-96.
8. Bonanno C, Wapner RJ. Antenatal corticosteroids in the management of preterm birth: are we back where we started? Obstet Gynecol Clin N Am. 2012;39(1):47-63.

9. Haram K, Mortensen JH, Magann EF, Morrison JC. Antenatal corticosteroid treatment: factors other than lung maturation. J Matern Fetal Neonatal Med. 2017:30(12):1437-41

10. French NP, Hagan R, Evans SF, Godfrey M, Newnham JP. Repeated antenatal corticosteroids: size at birth and subsequent development. Am J Obstet Gynecol. 1999;180(1 Pt 1):114-21.

11. C. McEvoy, D. Schilling, D. Peters, C. Tillotson, P. Spitale, L. Wallen, et al. Respiratory compliance in preterm infants after a single rescue course of antenatal steroids: a randomized controlled trial. Am J Obstet Gynecol, 202 (2010) 544.e1-9.

12. Garite TJ, Kurtzman J, Maurel K, Clark R. Impact of a 'rescue course' of antenatal corticosteroids: a multicenter randomized placebo-controlled trial. Obstetrix Collaborative Research Network. Am J Obstet Gynecol. 2009;200: 248 e1-9.

13. Crowther CA, Haslam RR, Hiller JE, Doyle LW, Robinson JS. Neonatal respiratory distress syndrome after repeat exposure to antenatal corticosteroids: a randomised controlled trial. Lancet. 2006;367(9526):1913-9.

14. Roberts D, Brown J, Medley N, Dalziel SR. Antenatal corticosteroids for accelerating fetal lung maturation for women at risk of preterm birth. Cochrane Database Syst Rev. 2017;3:CD004454.

15. Doyle LW, Ford GW, Rickards AL, Kelly EA, Davis NM, Callanan C, et al. Antenatal corticosteroids and outcome at 14 years of age in children with birth weight less than 1501 grams. Pediatrics. 2000;106(1):E2.

16. Wapner RJ, Sorokin Y, Thom EA, Johnson F, Dudley DJ, Spong CY, et al. Single versus weekly courses of antenatal corticosteroids: evaluation of safety and efficacy. Am J Obstet Gynecol. 2006;195(3):633-42.

17. Crowther CA, Doyle LW, Haslam RR, Hiller JE, Harding JE, Robinson JS, et al. Outcomes at 2 years of age after repeat doses of antenatal corticosteroids. N Engl J Med. 2007:357:1179-89.

18. Doell RG, Kretchmer N. Intestinal invertase: precocious development of activity after injection of hydrocortisone. Science. 1964;143:42-4.

19. Koldovski O, Sunshine P. Effect of cortisone on the developmental pattern of the neutral and the acid hgalactosidase of the small intestine of the rat Biochem J. 1970;117:467-71.

20. Villa M, Menard D, Semenza G, Mantei N. The expression of lactase enzymatic activity and mRNA in human fetal jejunum. Effect of organ culture and of treatment with hydrocortisone. FEBS Lett. 1992;301:202-6.

21. de Waard M, Li Y, Zhu Y, Ayede Al, Berrington J, Bloomfield FH, et al. Time to full enteral feeding for very low-birth-weight infants varies markedly among hospitals worldwide but may not be associated with incidence of necrotizing Enterocolitis: the NEOMUNE-NeoNutriNet cohort study. JPEN J Parenter Enteral Nutr. 2019;43(5):658-67.

22. Agostoni C, Buonocore G, Carnielli V, De Curtis M, Darmaun D, Decsi T, et al. Enteral nutrient supply for preterm infants: commentary from the European Society of Paediatric Gastroenterology, Hepatology and nutrition committee on nutrition. J Pediatr Gastroenterol Nutr. 2010;50:85-91.

23. Facco F, Louis J, Knavert MP, Izci Balserak B. Chapter 157 - SleepDisordered Breathing in Pregnancy. In: Kryger M, Roth T, Dement WC, editors. Principles and Practice of Sleep Medicine (Sixth Edition): Elsevier; 2017.p.1540-6.e4.

24. Patel AL, Engstrom JL, Meier PP, Kimura RE. Accuracy of methods for calculating postnatal growth velocity for extremely low birth weight infants. Pediatrics. 2005;116(6):1466-73.

25. Bauer CR, Morrison JC, Poole WK, Korones SB, Boehm JJ, Rigatto H, et al. A decreased incidence of necrotizing enterocolitis after prenatal glucocorticoid therapy. Pediatrics. 1984;73:682-8.

26. Thompson AM, Bizzarro MJ. Necrotizing Enterocolitis in Newborns Pathogenesis, Prevention and Management. Drugs. 2008;68(9):1227-38.

27. Berseth CL. Gastrointestinal motility in the neonate. Clin Perinatol. 1996; 23(2):179-90.

28. Menghua W, Yannan Z, Zheng Z. [Analysis of factors influencing feeding intolerance in preterm infants with different gestational ages]. Zhongnan Journal of Medical Sciences. 2017;DOl:https://doi.org/10.15972/j.cnki.431509/r.2017.02.013. 26. [in Chinese].

29. Norberg H, Stålnacke J, Heijtz RD, Smedler A-C, Nyman M, Forssberg H, et al. Antenatal corticosteroids for preterm birth: dose-dependent reduction in birthweight, length and head circumference. Acta Paediatr. 2011;100(3):364-9 
30. Aghajafari F, Murphy K, Matthews S, Ohlsson A, Amankwah K, Hannah M. Repeated doses of antenatal corticosteroids in animals: a systematic review. Am J Obstet Gynecol. 2002;186(4):843-9.

31. Thorp JA, Jones PG, Peabody JL, Knox E, Clark RH. Effect of antenatal and postnatal corticosteroid therapy on weight gain and head circumference growth in the nursery. Obstet Gynecol. 2002 Jan;99(1):109-15.

32. Battin M, Bevan C, Harding J. Growth in the neonatal period after repeat courses of antenatal corticosteroids: data from the ACTORDS randomised trial. Arch Dis Child Fetal Neonatal Ed. 2012;97(2):F99-105.

33. Fattal-Valevski A, Toledano-Alhadef H, Leitner Y, Geva R, Eshel R, Harel S, Growth patterns in children with intrauterine growth retardation and their correlation to neurocognitive development. J Child Neurol. 2009;24:846-51.

34. Bruschettini M, van den Hove DL, Gazzolo D, Steinbusch HW, Blanco CE. Lowering the dose of antenatal steroids: the effects of a single course of betamethasone on somatic growth and brain cell proliferation in the rat. Am J Obstet Gynecol. 2006;194(5):1341-6.

35. Gluckman PD, Hanson MA. Living with the past: evolution, development, and patterns of disease. Science. 2004;305(5691):1733-6.

36. Murphy K, Aghajafari F. Single versus repetitive courses of corticosteroids: what do we know? Clin Obstet Gynecol. 2003;46(1):161-73.

37. Blickstein I, Shinwell ES, Lusky A, Reichman B, Israel NN. Plurality-dependent risk of respiratory distress syndrome among very-low-birth-weight infants and antepartum corticosteroid treatment. Am J Obstet Gynecol. 2005;192(2): 360-4.

38. Quist-Therson EC, Myhr TL, Ohlsson A. Antenatal steroids to prevent respiratory distress syndrome: multiple gestation as an effect modifier. Acta Obstet Gynecol Scand. 1999;78:388-92.

39. Romejko-Wolniewicz E, Teliga-Czajkowska J, Czajkowski K. Antenatal steroids: can we optimize the dose? Curr Opin Obstet Gynecol. 2014;26(2):77-82.

40. Davidoff MJ, Dias T, Damus K, Russell R, Bettegowda VR, Dolan S, et al. Changes in the gestational age distribution among U.S. singleton births: impact on rates of late preterm birth, 1992 to 2002. Semin Perinatol. 2006; 30(1):8-15.

41. Wong D, Abdel-Latif M, Kent A. NICUS Network Antenatal steroid exposure and outcomes of very premature infants: a regional cohort study. Arch Dis Child Fetal Neonatal Ed. 2014;99:F12-20.

42. Travers CP, Carlo WA, McDonald SA, Das A, Bell EF, Ambalavanan N, et al. Mortality and pulmonary outcomes of extremely preterm infants exposed to antenatal corticosteroids. Am J Obstet Gynecol. 2018; 218 1:130 e1- e13.

43. Roberts D, Dalziel $S$. Antenatal corticosteroids for accelerating fetal lung maturation for women at risk of preterm birth. Cochrane Database Syst Rev. 2006;3:Cd004454.

\section{Publisher's Note}

Springer Nature remains neutral with regard to jurisdictional claims in published maps and institutional affiliations.

Ready to submit your research? Choose BMC and benefit from:

- fast, convenient online submission

- thorough peer review by experienced researchers in your field

- rapid publication on acceptance

- support for research data, including large and complex data types

- gold Open Access which fosters wider collaboration and increased citations

- maximum visibility for your research: over $100 \mathrm{M}$ website views per year

At $\mathrm{BMC}$, research is always in progress.

Learn more biomedcentral.com/submissions 